\title{
FAKTOR-FAKTOR YANG MEMPENGARUHI PERTUMBUHAN KAWASAN INDUSTRI DI SUMATERA UTARA
}

\author{
Nina Purnasari' ${ }^{1}$, Friska Darnawaty ${ }^{2}$ \\ Universitas Prima Indonesia \\ nina.sinuhaji.84@gmail.com \\ friskadarnawaty1704@gmail.com
}

\begin{abstract}
ABSTRAK
Pembangunan kawasan industri menjadi faktor dari peningkatan pertumbuhan ekonomi, yang diharapkan mampu memberikan kontribusi yang berarti terhadap Produk Domestik Regional Bruto (PDRB), dan meningkatkan jumlah tenaga kerja sektor industri terhadap total tenaga kerja secara nasional. Dengan meningkatnya penyerapan tenaga kerja dan pendapatan masyakat di suatu wilayah mengalami perubahan kondisi sosial yang diharapkan mampu mengurangi tingkat pengangguran yang masih belum teratasi oleh pemerintah. Semakin banyak jumlah penduduk menunjukkan jumlah tenaga kerja terhadap keberadaan industrialisasi akan semakin bertambah. Hasil analisis menunjukkan bahwa kawasan industri mempunyai peranan penting dalam peningkatan output perekonomian dan penyerapan tenaga kerja yang lebih besar.
\end{abstract}

Kata Kunci: Penduduk, Pengangguran, Industri, PDRB

\section{ABSTRACT}

The development of industrial estates is a factor of increasing economic growth, which is expected to be able to make a meaningful contribution to the Gross Regional Domestic Product (GRDP), and increase the number of industrial sector workers to the total workforce nationally. With the increase in employment and community income in a region experiencing changes in social conditions that are expected to reduce the unemployment rate that is still not resolved by the government. The more population shows the number of workers towards the existence of industrialization will increase. The analysis shows that the industrial estate has an important role in increasing economic output and greater employment.

Keywords: Population, Unemployment, Industry, GRDP

\section{PENDAHULUAN}

Pembangunan kawasan industri merupakan salah satu sarana untuk mengembangkan industri yang berwawasan lingkungan serta memberikan kemudahan dan daya tarik untuk berinvestasi. Hal ini sejalan dengan amanat dalam UndangUndang Nomor 5 Tahun 1984 tentang Perindustrian bahwa upaya untuk mendorong pembangunan industri perlu dilakukan melalui pembangunan lokasi industri yaitu berupa Kawasan Industri.

Guna mendorong percepatan pembangunan kawasan industri dimaksud, pemerintah telah menerbitkan Peraturan Pemerintah Nomor 24 Tahun 2009 tentang Kawasan Industri, di mana setiap perusahaan industri baru setelah diberlakukannya Peraturan Pemerintah tersebut, wajib masuk dalam 
Kawasan Industri. Dasar pertimbangan mewajibkan industri baru masuk dalam kawasan industri agar industri yang dibangun berada dalam tata ruang yang tepat dan benar, akrab lingkungan, pengelolaan yang efektif dan efisien serta memudahkan dalam perencanaan dan pengadaan infrastruktur yang diperlukan. (Kemenperin, 2010).

(UNIDO, 2012) membedakan tujuan pembangunan kawasan industri di negara maju dan berkembang. Di negara maju bertujuan untuk meminimalkan eksternalitas negatif (seperti polusi dan kemacetan), sehingga kawasan industri direncanakan sebagai klaster pergudangan dan pusat distribusi, bahkan pada beberapa negara, kawasan industrinya dikonversi menjadi eco industrial park, sedangkan di negara berkembang kawasan industri bertujuan untuk:

1. mendorong pertumbuhan ekonomi dan lapangan kerja di tingkat nasional, regional, dan lokal;

2. menarik investasi asing; dan

3. memacu perkembangan sektor industri.

Keberadaan kawasan industri di daerah dapat berperan sebagai mesin penggerak ekonomi (engine of growth) daerah melalui perluasan lapangan usaha dan kesempatan kerja berbasis sektor industri. Sektor ini layak dikembangkan menjadi tulang punggung perekonomian, hal ini dapat dilihat dari kontribusinya terhadap peningkatkan Produk Domestik Regional Bruto (PDRB) Provinsi Sumatera Utara. Hal inilah yang mendorong Provinsi Sumatera Utara untuk merencanakan pengembangan kawasan industri.
Pengembangan kawasan industri di Provinsi Sumatera Utara telah didukung oleh kesediaan masyarakat lokal untuk dikembangkan kawasannya sebagai kawasan industri serta peluang penyediaan infrastruktur jalan baru kedepannya. Selain itu, pemanfaatan Kawasan Industri juga diharapkan bukan hanya dapat mengatasi permasalahan pengangguran namun dapat mengurangi dampak-dampak negatif dari industri yang tidak terkonsentrasi pada satu lokasi.

Dengan berdirinya pabrikpabrik di dalam kawasan industri akan memberikan efek multiplier yang sangat besar dan dapat mendukung peningkatan pertumbuhan ekonomi daerah. Sumbangan dari kawasan industri dalam memajukan ekonomi daerah antara lain adalah meningkatnya produk domestik regional bruto (PDRB), terserapnya tenaga kerja, timbulnya wirausaha-wirausaha baru, naiknya daya beli masyarakat, berkembangnya pasar dan lembaga keuangan, dan lainlain.

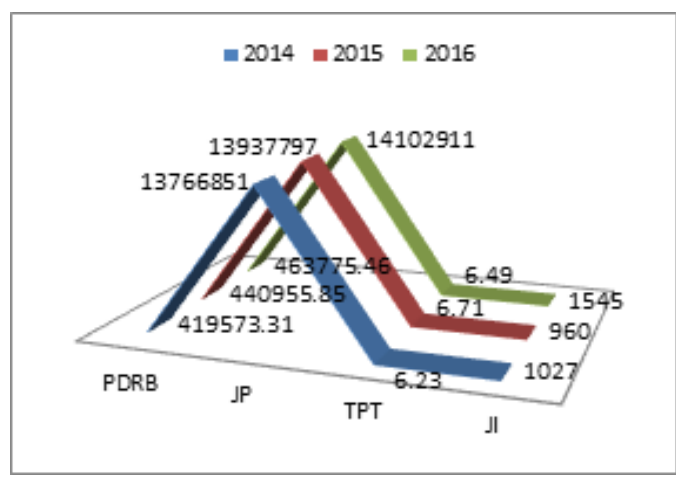

Sumber: BPS Sumatera Utara

Gambar 1. Faktor-faktor

Pertumbuhan Kawasan Industri Di Sumatera Utara 
Kondisi Pertumbuhan ekonomi di Sumatera Utara pada tahun 2015 yang berpengaruh terhadap jumlah penduduk, tingkat pengangguran terbuka, dan jumlah industri yang menunjukkan fenomena di Sumatera Utara masih tertekannya jumlah industri yang menjadi penyebab tertahannya pertumbuhan ekonomi Sumatera Utara di sisi ketersediaan lapangan pekerjaan yang akan berakibat terhadap kondisi tingkat pengangguran terbuka di provinsi Sumatera Utara meningkat. Sejalan dengan itu, tingkat kesejahteraan juga menurun yang tercermin dari peningkatan persentase penduduk. Meskipun telah banyak daerah yang menyadari pentingnya manfaat keberadaan kawasan industri bagi pembangunan di daerahnya, dengan berlomba-lomba mendirikan kawasan industri. Namun masih banyak daerah yang belum mendukung dan memanfaatkan keberadaan kawasan industri sebagai sarana daya tarik investasi, meskipun di daerah tersebut telah ada kawasan industrinya. Efek dari penempatan industri seperti kawasan industri berlipat ganda berkenaan dengan pengembangan dan daya saing suatu kawasan.

Adapun tujuan penelitian ini dapat dijadikan bahan masukan pemerintahan daerah Sumatera Utara untuk memajukan pertumbuhan kawasan industri diharapkan dapat meningkatkan pertumbuhan ekonomi daerah Sumatera Utara melalui analisis pengaruh pertumbuhan jumlah penduduk, tingkat pengangguran terbuka, jumlah industri terhadap Produk Domestik Regional Bruto di Sumatera Utara. $\begin{array}{lrr}\begin{array}{l}\text { Keseriusan } \\ \text { pengembangan }\end{array} & \text { pemerintah } & \text { dalam } \\ \text { Kawasan } & \text { Industri }\end{array}$ bukanlah suatu hal yang mengherankan melihat dampak positif/keuntungan yang dapat diperoleh dari pengembangan Kawasan Industri bagi perkembangan lingkungan di sekitarnya.

Untuk mengetahui pertumbuhan ekonomi regional, digunakanlah data Produk Domestik Regional Bruto (PDRB) dapat didefinisikan sebagai nilai barang dan jasa akhir yang dihasilkan oleh sistem perekonomian di suatu wilayah atau daerah dalam kurun waktu tertentu. Hasil penelitian ini sejalan dengan hasil kajian (Zhou \& Huang, 2019) yang meneliti dampak investasi pemerintah pada pembangunan 110 kawasan industri baru di 8 kota besar di Cina terhadap penyediaan lapangan kerja industri pengolahan. Salah satu temuan dalam penelitian tersebut adalah pembangunan kawasan industri tersebut mampu memberikan kontribusi yang besar terhadap peningkatan penyerapan tenaga kerja.

Demikian pula hasil penelitian (Vidová, 2010) yang meneliti perkembangan kawasan industri dan pengaruhnya terhadap penciptaan lapangan kerja di Slovakia. Kawasan industri di Slovakia membuka peluang bagi masuknya investasi asing dan menurunkan tingkat pengangguran dengan adanya sarana penciptaan lapangan kerja baru. Pembangunan kawasan industri di Slovakia berkontribusi terhadap penciptaan lapangan kerja baru, yang sebagian besar lapangan kerja baru tersebut tersedia di wilayah yang terdapat kawasan industri. Hasil ini sejalan dengan pemikiran 
(Mulyadi, 2012) bahwa industri pengolahan yang berlokasi di dalam kawasan industri akan memacu pertumbuhan ekonomi yang lebih tinggi.

Menurut hasil penelitian (Tetty \& Yeni, 2019) ditemukan bahwa jumlah industri memberikan pengaruh yang negatif signifikan terhadap pertumbuhan ekonomi Hal ini berarti peningkatan jumlah industri akan menyebabkan pertumbuhan ekonomi industri mengalami peningkatan. Semakin besar pertumbuhan jumlah industri dalam hal ini berpengaruh negatif dikarenakan harus didukung oleh jumlah investasi di sektor industri baik yang berasal dari dalam negeri maupun luar negeri maka akan semakin besar pertumbuhan PDRB di Kabupaten/Kota Sumatera Utara.

\section{Penentuan}

pertumbuhan kawasan industri dapat dilihat juga dari sektor unggulan apa yang mampu mendatangkan pendapatan bagi daerah tersebut dengan mengandalkan sumber daya dan tenaga kerja dari penduduk lokal. Hasil dari sektor unggulan ini dapat menjadi sumber pendapatan dari perdagangan baik nasional maupun internasional.

Ekonomi lokal suatu wilayah berperan penting dalam meningkatkan kesejahteraan penduduk lokal. Untuk itu, perlu untuk mengetahui kondisi kekuatan, kelemahan dan perubahan yang terjadi dalam perekonomian lokal suatu wilayah (Klosterman, 1990). Pertumbuhan ekonomi wilayah dapat ditingkatkan melalui sektor ekonomi unggulan yang memiliki potensi daya saing komparatif karena memiliki efek pengganda yang besar (Amalia, 2012). Diversifikasi sektor ekonomi menunjukkan bahwa ada ketergantungan spesialisasi ekonomi antar wilayah yang dapat meningkatkan kondisi perekonomial lokal (Fattah \& Rahman, 2013). Diperlukan peran pemerintah lokal, komunitas, dan pihak swasta dalam memanajemen sumber daya lokal yang dimiliki. Selain akan menciptakan lapangan pekerjaan baru, langkah tersebut juga akan menggenerator perkembangan aktivitas ekonomi wilayah tersebut (Arsyad, 2016). Dengan dasar pemikiran ini, maka menemukan sektor unggulan suatu daerah merupakan langkah penting dalam menentukan prioritas pembangunan atau rencana pembangunan suatu daerah.

\section{KERANGKA PEMIKIRAN}

Pengembangan kawasan industri memberikan kontribusi yang besar terhadap pembentukan PDRB di Sumatera Utara. Dengan adanya pengembangan kawasan industri diharapkan mampu menyerap tenaga kerja yang banyak dan tingkat pengangguran berkurang.

Adapun kerangka konseptual dari variabel-variabel yang diteliti dalam tulisan ini, dapat digambarkan dalam Gambar 2 berikut:

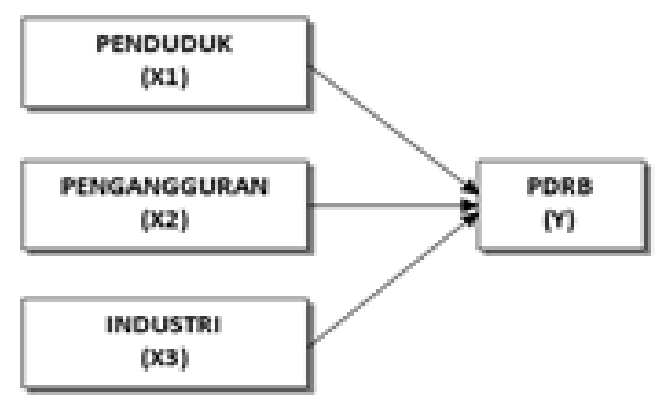

Gambar 2. Diagram Kerangka Pemikiran 


\section{METODOLOGI PENELITIAN}

Penelitian ini dilakukan untuk mengkaji tentang bagaimana jumlah penduduk, tingkat pengangguran terbuka,danjumlahindustri,berpengaruh terhadap produk domestik regional bruto (PDRB) di Sumatera Utara. Dalam penelitian ini menggunakan data sekunder dan data runtun waktu (time series) pada kurun waktu 2006-2016 Model analisis yang digunakan adalah model analisis dengan menggunakan metode kuantitatif Analisis Regresi Berganda (Multiple Regression) dengan metode Ordinary Least Square (OLS) atau metode kuadrat terkecil biasa untuk mendapatkan koefisien garis regresi berganda.

Spesifikasi model untuk mengatahui varibel yang mempengaruhi PDRB di Sumatera Utara selama tahun 2006-2016 yang digunakan dalam penelitian ini adalah:

$P D R B=f(J P, T P T, I N D)$.

Kemudian fungsi tersebut dinyatakan dalam hubungan $\mathrm{Y}$ dan $\mathrm{X}$ maka,

PDRB $=\alpha J P^{\beta 1} e^{\beta 2 T P T+\beta 3 I N D+\mu}$

Kemudian dari fungsi tersebut ditransformasi ke dalam model persamaan ekonometrika dalam bentuk linier berganda menjadi:

$$
\begin{aligned}
& \operatorname{Ln}(P D R B)_{t}=\beta_{0}+\beta_{1} \operatorname{Ln}(J P)+\beta_{2} \operatorname{Ln}(T P T)_{t}+ \\
& \beta_{3} \operatorname{Ln}(I N D)_{t}+e_{t} \ldots \ldots \ldots \ldots . .(3.3)
\end{aligned}
$$

\section{Uji Penyimpangan Asumsi Klasik}

Berdasarkan keadaan tersebut di dalam ilmu ekonometrika, agar suatu model dikatakan baik dan efisien maka perlu dilakukan pengujian sebagai berikut: (Widarjono, 2013)

\section{Uji Normalitas}

Untuk menguji normalitas data pada penelitian ini, menggunakan uji Karque-Bera. Kriteria yang digunakan adalah jika nilai probabilitas JarqueBera (JB) test $>$ alpha $(0,05)$, maka data dikatakan berdistribusi normal.

\section{Uji Multikolinieritas}

Pengujian asumsi klasik Multikolinieritas dapat dilihat dari korelasi variabel-variabel bebas dengan matriks korelasi. Apabila antar variabel bebas memiliki koefisien korelasi di atas 0,9 hal ini menunjukkan adanya multikolinieritas. Selain itu dapat digunakan dengan menghitung nilai Variance Inflastion Factor (VIF) dan Tolerance (TOL).

\section{Uji Autokorelasi}

Pengujian ada atau tidaknya autokorelasi dalam persamaan regresi ini dilakukan dengan melihat keadaan nilai Durbin Watson (DW test). Jika DW hitung terletak lebih kecil dari dL terjadi autokorelasi positif, di antara dL dan dU tidak dapat diputuskan, di antara $\mathrm{dU}<$ DW < 4-dU maka bebas autokorelasi, di antara 4-dU dan 4-dL maka tidak dapat diputuskan, lebih dari 4-dL maka terjadi autokorelasi negatif (Gujarati, et al 2012). Metode yang digunakan untuk mendekteksi autokorelasi dilakukan dengan cara, yaitu LM Test.

\section{Uji Statistik}

Uji statistik atas model penelitian ini dilakukan dengan uji koefisien determinan $\left(\mathrm{R}^{2}\right)$, uji tstatistik dan uji Fstatistik. Besarnya nilai $\mathrm{R}^{2}$ adalah $0<\mathrm{R}^{2}<1$, apabila nilainya mendekati 1 
maka model tersebut dapat dikatakan baik, karena semakin dekat hubungan atar variabel independen dengan variabel dependen, dan sebaliknya jika nilainya semakin mendekati nol maka berarti semakin jauh hubungan antar variabel independen dengan variabel dependen sehingga model kurang baik.

\section{HASIL DAN PEMBAHASAN}

Hasil analisis regresi terhadap model estimasi yang digunakan dalam penelitian ini seperti tampak pada tabel berikut:

\section{Tabel 1 Hasil Estimasi Regresi dengan Metode Linier Berganda (OLS)}

\begin{tabular}{|c|c|c|c|c|}
\hline Variable & Coefficient & $\begin{array}{l}\text { Std. } \\
\text { Error }\end{array}$ & t-Statistic & Prob. \\
\hline PDRB & -230.0557 & 19.34162 & -11.89434 & 0.0000 \\
\hline LJI & -0.069080 & 0.623799 & -0.110740 & 0.9135 \\
\hline LJP & 14.75934 & 1.288554 & 11.45419 & 0.0000 \\
\hline LTPT & 0.261064 & 0.214063 & 1.219567 & 0.2443 \\
\hline R-squared & 0.930113 & \multicolumn{2}{|c|}{ Mean dependent var } & 11.50257 \\
\hline $\begin{array}{l}\text { Adjusted } \\
\text { R-squared }\end{array}$ & 0.913985 & \multicolumn{2}{|c|}{ S.D. dependent var } & 0.951148 \\
\hline $\begin{array}{l}\text { S.E. of } \\
\text { regression }\end{array}$ & 0.278955 & \multicolumn{2}{|c|}{ Akaike info criterion } & 0.486791 \\
\hline $\begin{array}{l}\text { Sum } \\
\text { squared } \\
\text { resid }\end{array}$ & 1.011606 & \multicolumn{2}{|c|}{ Schwarz criterion } & 0.682841 \\
\hline $\begin{array}{l}\text { Log likeli- } \\
\text { hood }\end{array}$ & -0.137725 & \multicolumn{2}{|l|}{ F-statistic } & 57.67169 \\
\hline $\begin{array}{l}\text { Durbin- } \\
\text { Watson stat }\end{array}$ & 1.203087 & \multicolumn{2}{|c|}{ Prob(F-statistic) } & 0.000000 \\
\hline
\end{tabular}

Sumber : Eviews 9.0 (data diolah)

Hasil analisis Regresi Linier Berganda dapat dituliskan dalam persamaan linear sebagai berikut:

PDRB = -230.0557-0.069080(JI)+14.7

$$
5934(\text { JP })+0.261064(\text { TPT })+\mathbf{e}_{\mathbf{t}}
$$

Dari hasil estimasi dapat diketahui bahwa jumlah industri tidak berpengaruh terhadap pertumbuhan ekonomi, sedangkan jumlah penduduk berpengaruh signifikan positif terhadap pertumbuhan ekonomi. Dan tingkat pengangguran terbuka tidak berpengaruh terhadap pertumbuhan ekonomi.

Tujuan utama dari usahausaha pembangunan ekonomi selain menciptakan pertumbuhan yang setinggi-tingginya, mengurangi tingkat kemiskinan, ketimpangan pendapatan, dan tingkat pengangguran.

Industri merupakan salah satu sektor yang memiliki peranan penting dalam pembangunan suatu wilayah dan peningkatan pendapatan masyarakat. Namun, pada penelitian ini jumlah industri tidak berpengaruh signifikan terhadap pembangunan ekonomi dikarenakan faktor kurangnya sektor unggulan yang dapat membawa perubahan mendasar dalam pertumbuhan kawasan industri. Dampak ekonomi yang dibawakan oleh pengembangan kawasan industri di suatu tempat terungkap antara lain dalam bentuk peningkatan produksi yang berpengaruh terhadap sumber daya dan pendapatan daerah.

Seperti hal nya pada hasil penelitian (Andreas et al, 2017) bahwa perubahan mendasar dalam periode jangka panjang dalam struktur ekonomi suatu negara maupun masyarakat yang dititik beratkan dan didominasi pada sektor pertanian dapat membawa perubahan ekonomi tradisional kawasan industri.

Selain sektor pertanian dan jasa 
yang menyumbang penyerapan tenaga kerja di Provinsi Sumatera Utara, sektor industrijuga berperan dalam mengurangi angka pengangguran melihat dari serapan tenaga kerjanya. Masyarakat dari desa tidak lagi hanya menargetkan kota sebagai tempat mencari pekerjaan, tetapi cukup ke Kawasan Industri yang menyediakan lapangan kerja cukup banyak. Hasil penelitian ini menyatakan bahwa jumlah pengangguran tidak berpengaruh terhadap pertumbuhan ekonomi, hal ini disebabkan kurangnya jumlah produksi sumber daya yang akan dihasilkan oleh sektor industri mengakibatkan pendapatan suatu wilayah tidak bertambah.

Menurut (Djojodipuro, 1992) bahwa keadaan tersebut akan mendorong adanya perluasan peluang kerja yang pada akhirnya akan meningkatkan pendapatan dan permintaan masyarakat (daya beli). Adanya peningkatan pendapatan dan daya beli (permintaan) tersebut menunjukan bahwa perekonomian itu tumbuh dan sehat.

Perkembangan dan peningkatan jumlah penduduk di Provinsi Sumatera Utara harus diimbangi dengan terbuka lebarnya penyediaan kesempatan kerja agar pengangguran tidak semakin luas. Para warga kota yang bekerja di Kawasan Industri juga cenderung akan memilih tinggal di daerah Kawasan Industri apabila Kawasan Industri telah menyediakan fasilitas hunian yang memadai. Sehingga peluang arus transmigrasi dari kota ke daerah pinggiran kota menjadi semakin besar yang tentu saja dapat mengurangi kepadatan penduduk kota sebagai nilai positifnya.
Tabel 2 Hasil Uji Klasik

\begin{tabular}{|c|c|c|c|c|}
\hline \multicolumn{5}{|c|}{ UJI NORMALITAS } \\
\hline \multicolumn{2}{|c|}{ Jarque-Bera } & \multicolumn{3}{|c|}{2.265675} \\
\hline \multicolumn{2}{|c|}{ Probability } & \multicolumn{3}{|c|}{0.322118} \\
\hline \multicolumn{5}{|c|}{ UJI MULTIKOLINEARITAS } \\
\hline PDRB & 1 & 0.469896 & 0.960269 & 0.098570 \\
\hline JI & 0.469896 & 1 & 0.490127 & 0.075559 \\
\hline JP & 0.960269 & 0.490127 & 1 & 0.009914 \\
\hline TPT & 0.098570 & 0.075559 & 0.009914 & 1 \\
\hline \multicolumn{3}{|c|}{ HETEROSKEDASTISITAS } & \multicolumn{2}{|c|}{ AUTOKORELASI } \\
\hline \multicolumn{2}{|c|}{ F-statistic } & 9.148759 & \multicolumn{2}{|c|}{1.507076} \\
\hline \multicolumn{2}{|c|}{ Obs*R-squared } & 15.32492 & \multicolumn{2}{|l|}{3.656346} \\
\hline \multicolumn{2}{|c|}{ Prob. F } & 0.0026 & \multicolumn{2}{|l|}{0.2640} \\
\hline \multicolumn{2}{|c|}{ Prob. Chi-Square } & 0.0531 & \multicolumn{2}{|l|}{0.1607} \\
\hline \multicolumn{2}{|c|}{ Prob(F-statistic) } & 0.002581 & \multicolumn{2}{|l|}{0.699552} \\
\hline \multicolumn{2}{|c|}{$\begin{array}{l}\text { Durbin-Watson } \\
\text { stat }\end{array}$} & 1.601699 & \multicolumn{2}{|l|}{1.968301} \\
\hline
\end{tabular}

\section{KESIMPULAN}

Berdasarkan hasil penelitian mengenai faktor-faktor yang mempengaruhi perkembangan kawasan industri terhadap pertumbuhan ekonomi di Sumatera Utara dapat ditarik beberapa kesimpulan sebagai berikut:

1. Krisis moneter tahun 1997, membuat perekonomian Indonesia terpuruk dan mengalami pertumbuhan yang negatif.

2. Faktor-faktor yang memengaruhi perkembangan kawasan industri manufaktur di Sumatera Utara yaitu semakin besar skala usaha maka semakin meningkatkan konsentrasi industri; semakin beragam semakin mendukung aglomerasi industri; semakin tinggi orientasi semakin tinggi indeks spesialisasi industri; upah yang rendah mendukung terjadinya aglomerasi industri; 
konsentrasi industri memerlukan dukungan tingkat pendidikan tenaga kerja yang lebih tinggi; besarnya pasar akan memengaruhi pemilihan lokasi industri).

\section{SARAN}

Berdasarkan pembahasan dan kesimpulan yang dirumuskan sebelumnya, maka diberikan beberapa saran yang menyangkut penelitian ini, yaitu sebagai berikut:

1. Selain mengejar pertumbuhan, pemerataan pembangunanhendaknya juga menjadi perhatian pemerintah. Dalam rangka pemerataan pembangunan maka perlu adanya pemerataan fasilitas infrastruktur dan penciptaan aglomerasi industri di daerah-daerah yang memiliki potensi. Dalam jangka panjang interkoneksi berbagai infrastruktur tersebut secara meluas akan memberikan potensi pertumbuhan yang lebih baik dibandingkan jika terpusat.

2. Berkaitan dengan perekonomian Indonesia yang masih bersifat padat karya (labor intensive) maka untuk mendorong pertumbuhan ekonomi diprioritaskan pada kegiatan ekonomi dan industri-industri yang menyerap banyak tenaga kerja. Pengembangan industri padat karya seharusnya dilakukan dalam rentang waktu yang panjang dan continuous karena Indonesia memiliki jumlah tenaga kerja yang banyak dan terus meningkat.

3. Pemerintah lebih memperhatikan aspek peningkatan sumber daya manusia. Karena sumber daya manusia merupakan variabel penting dan terbukti dapat meningkatkan pertumbuhan ekonomi dan terciptanya konsentrasi kegiatan ekonomi. Perlu adanya reposisi kebijakan pendidikan di Indonesia, dengan memandang bahwa pendidikan merupakan investasi. Konsekuensi dari reposisi yaitu perlu ditetapkan dan disosialisasikan standar pelayanan minimum pendidikan pada berbagai jenis dan jenjang pendidikan di Indonesia, yang mencakup aspek equity, efisiensi, partisipasi, kualitas dan sustabiability.

\section{DAFTAR PUSTAKA}

Amalia, F. (2012). Penentuan Sektor Unggulan Perekonomian Wilayah Kabupaten Bone Bolango Dengan Pendekatan Sektor Pembentuk Pdrb. Etikonomi, 11(2), 196-207. https://doi.org/10.15408/etk. v11i2.1893

Andreas Rasu, Noortje Marsellanie Benu, E. P. M. (2017). Dampak Industri PT. Global Coconut

(Andreas Rasu, Noortje Benu, Elsje Manginsela ). 13, 99-112.

Damodar N. Gujarati and Dawn C. Porter. (2012). Dasar-dasar Ekonometrika. Jakarta: Salemba Empat.

Djojodipuro, M. (1992). Teori lokasi.

Fakultas Ekonomi Universitas Indonesia.

Fattah, S., \& Rahman, A. (2013). Analysis of Regional Economic Development in the Regency / 
Municipality at South Sulawesi icoeme-19.2019.44

Province In Indonesia. Journal of Economics and Sustaonable

Development, 4(1), 1-10.

Kemenperin. (2010). Lampiran

Permenperin No. 35/M-IND/

PER/3/2010 Tentang Pedoman

Teknis Kawasan Industri.

Kementrian Perindustrian, (35).

Klosterman, R. (1990). Community

Analysis and Planning Techniques

(50185th Ed). Rowman \& Littlefield Publishers.

Lincolin Arsyad. (2016). Pengantar Perencanaan Pembangunan

Ekonomi Daerah (Edisi Keti).

Yogyakarta: BPFE.

Mulyadi, D. (2012). Manajemen perwilayahan industri. Jakarta:

Leuser Cita Pustaka.

Tetty, S., \& Yeni, S. (2019). Analisis

Determinan Pertumbuhan Industri

Provinsi Sumatera Utara. 3(2), 100-109.

UNIDO. (2012). Europe and Central

Asia Regional Conference on Industrial Parks. 79.

Vidová, J. (2010). Industrial parks history, present and its influence to the employment. Review of Economic Perspectives, 10(1), 41-58. https://doi.org/10.2478/ v10135-009-0008-1

Widarjono, A. (2013). Ekonometrika. Yogyakarta: UPP STIM YKPN.

Zhou, D., \& Huang, M. (2019). The Research on Coupling Level Difference and Path of Human Capital and Economic Growth in China's Five Urban Agglomerations. 85(Icoeme), 223-234. https://doi.org/10.2991/ 